\title{
تعليم اللغة العربية للناطقين بغيرها بين تهديات الواقع وأفاق
}

\author{
الاسمتقبل \\ اعتصات \\ العربيى الحضغراوبي \\ كلية الآداب والعلوم الإنسانية جامعة محمد الخامس الرباط

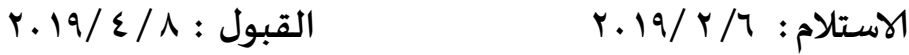

المستخلص :

تعتبر اللغة اليوم من الحاجات الأساسية للإنسان بحيث تربط بينهما علاقة

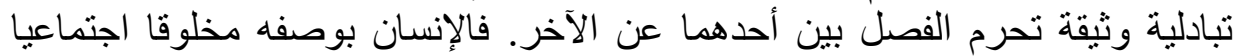

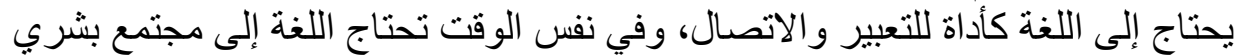

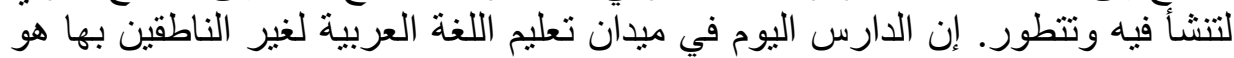





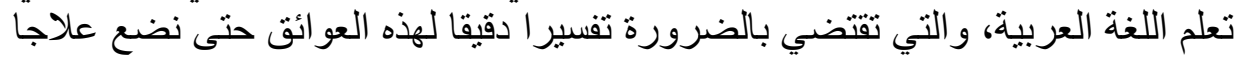

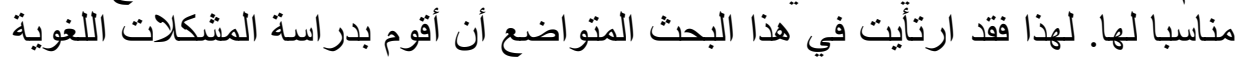

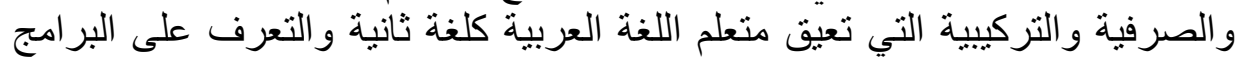

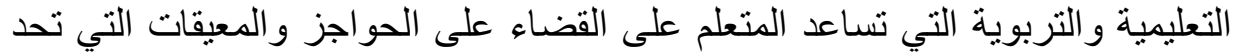
من عملية التعلم؛ والتعرف على ألهم الأسباب وإيجاد الحلول المناسبة في هذا البحث البح الكلمات المفتاحية: المشكلات اللغوية، التراكيب، الصرف، التحديات، أساليب العلاج، عملية التعلم

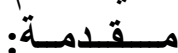

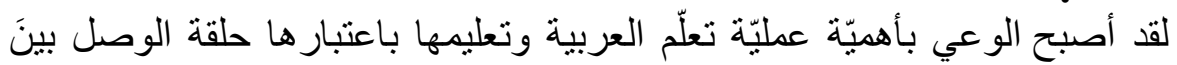

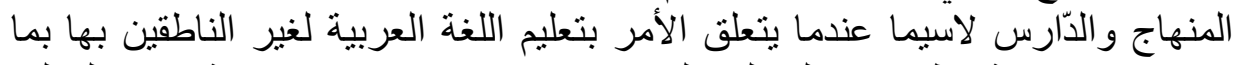

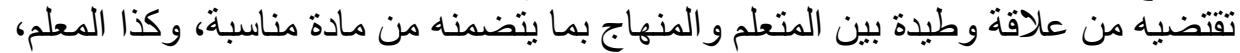

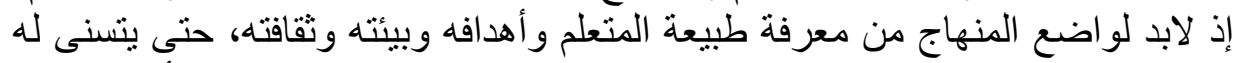

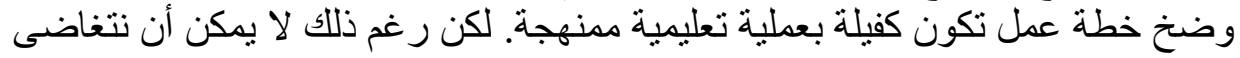

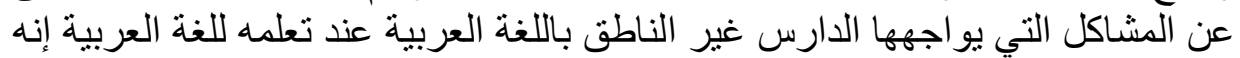
يتأثر بلغته الأم وينقل بعض الجوانب اللغوية إلى اللغة العربية فمثلا يحاول أن ينقل 


\section{العربي الحضراوي - (المي}

أصو ات لغته الأم أو يحاول استخدام تر اكيبه المعروفة في لغته كأن يجمع بعض الكلم الكمات

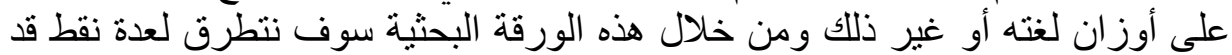

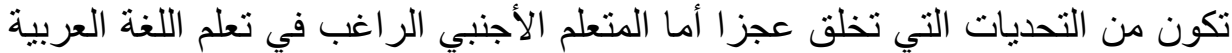

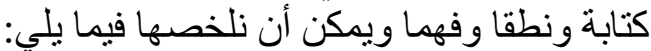
ا. ما هي المشكلات التي تواجه المعلم التقائم على تدريس اللغة العربية للناطقين

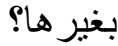

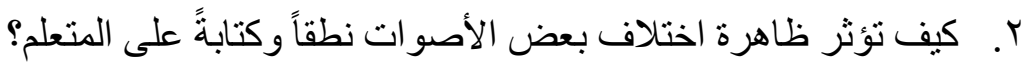
r. ما هي المشكلات التي يو اجهها الطلاب، وهم يتعلمون مهار ات الكتابة باللغة

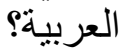

؟. ماذا نعلم من القو اعد و التر اكيب اللغوية؟ وكيف نعمهها؟

๑. ما مدى اختلاف مستوى الطلاب اللغوي في الصف الو احد على المدرس؟ 7. ما هي الحلول المقترحة التي تساهم في تحسين تعلم اللغة العربية للناطقين بغير ها؟ ! ـ المشكلات التي تواجه المعلم القائم على تدريس اللغة العربية للناطقين بغيرها من أهم مظاهر الحضارة في الربع الأخير من هذا القرن الاهتمام الواضح بتدريس

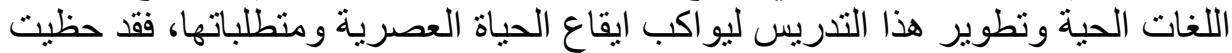

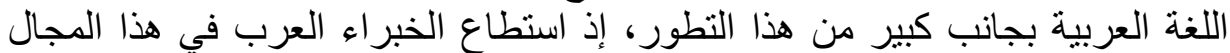

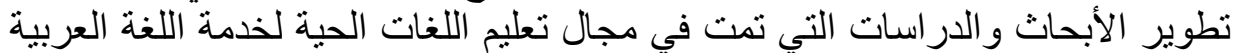

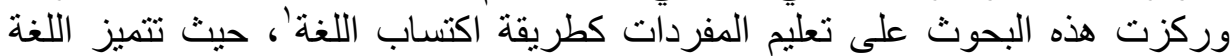

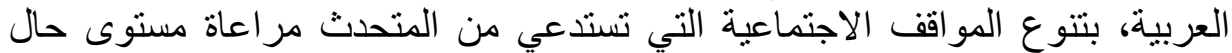

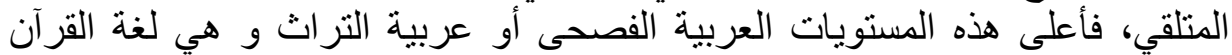

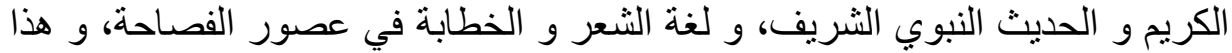

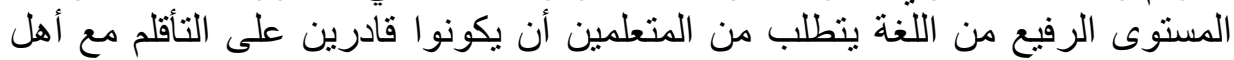

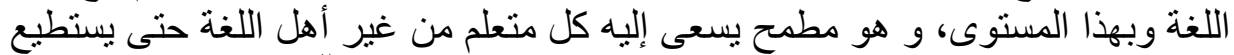

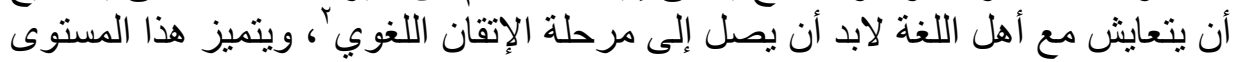

1 ـ العصيلي عبد العزيز بن ابراهيم ( . . . T) ، أساسيات تعليم اللغة العربية للناطقين بلغات

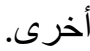

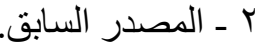


باستعمال العربية الفصحى، و الابتعاد قدر الإمكان عن الكلمات و الأساليب الاخيلة، مع الالتز ام بقو اعد اللغة العربية.

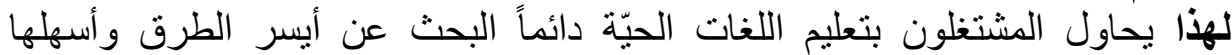

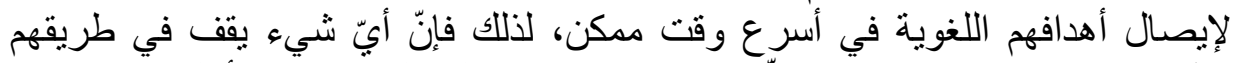

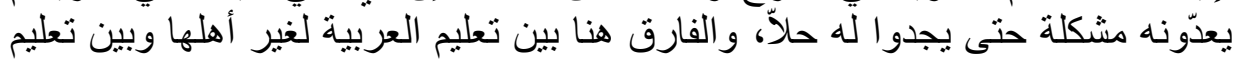

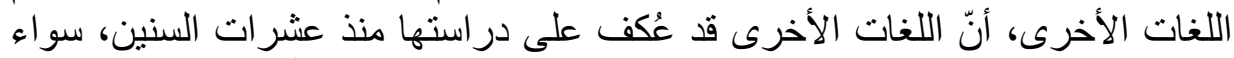

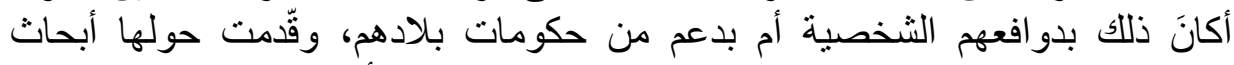

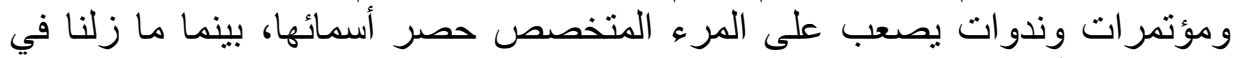

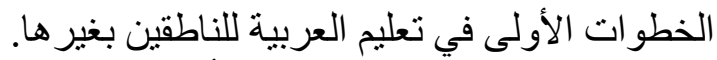

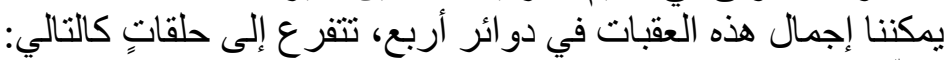

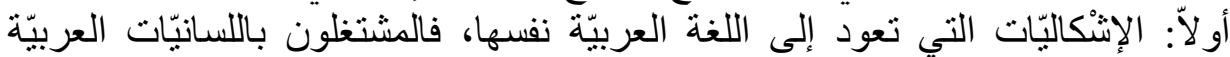

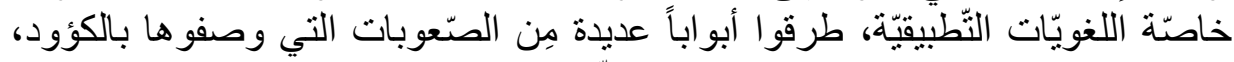

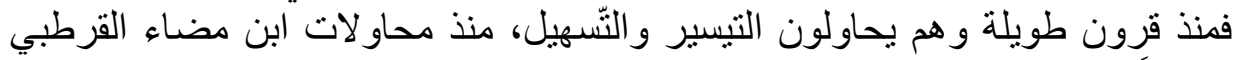

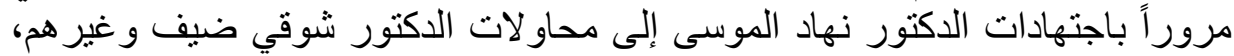

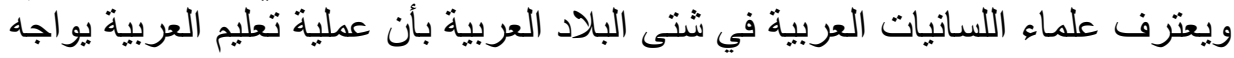

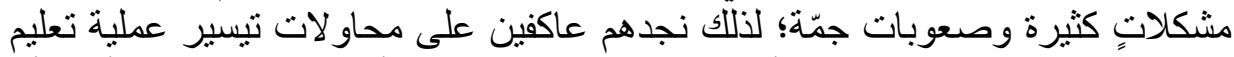

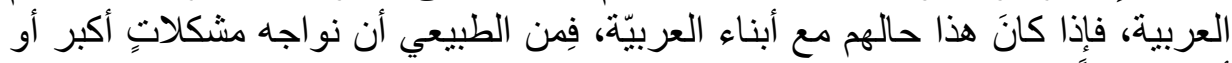

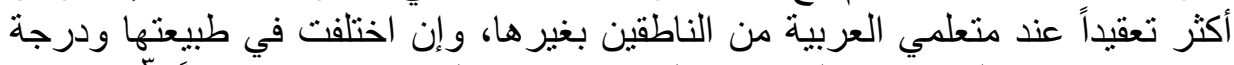

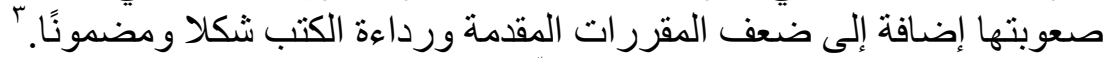

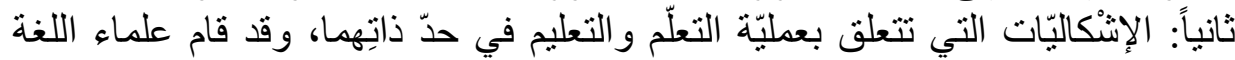

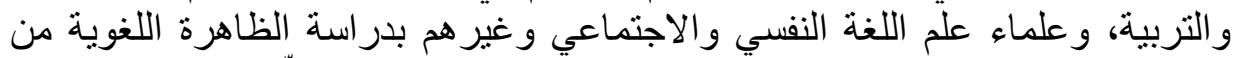

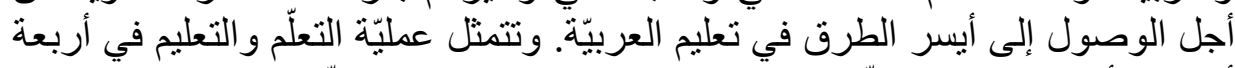

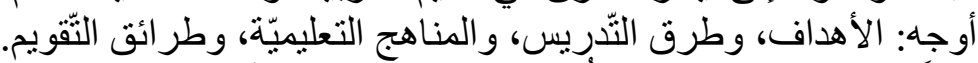

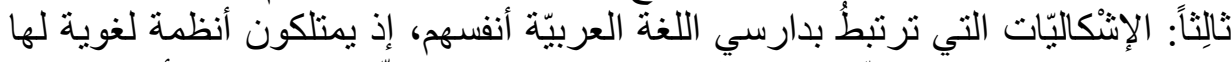

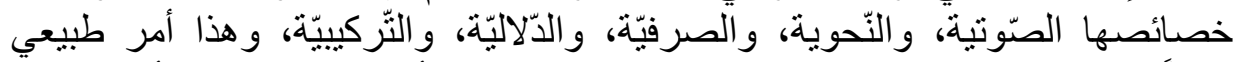

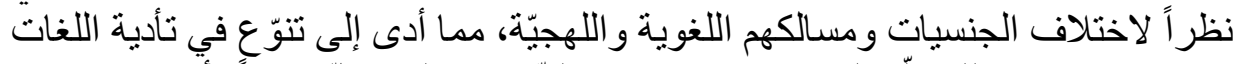

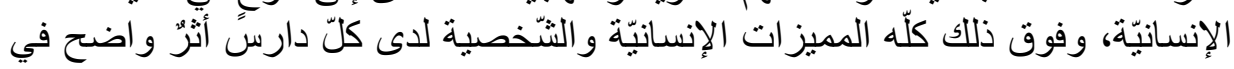
حدوث هذا التباين.



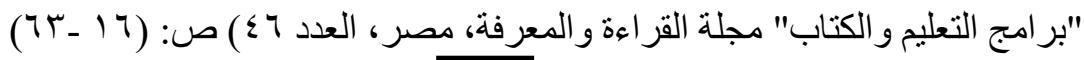




\section{العربي الحضراوي}

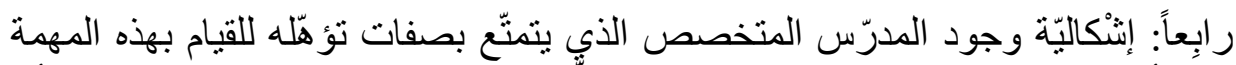

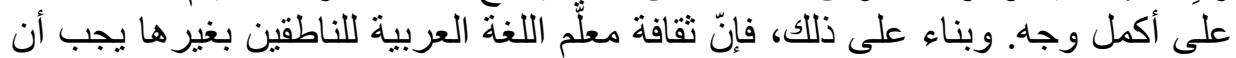

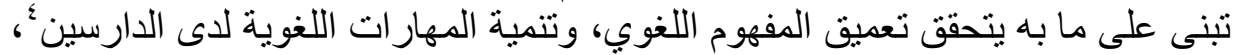

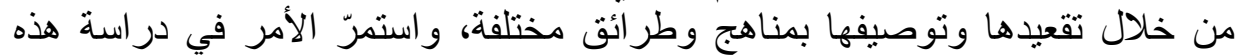

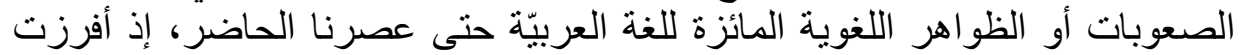



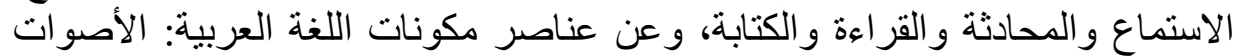

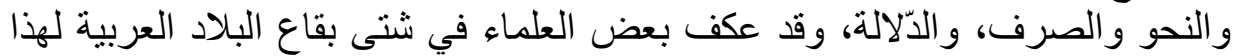

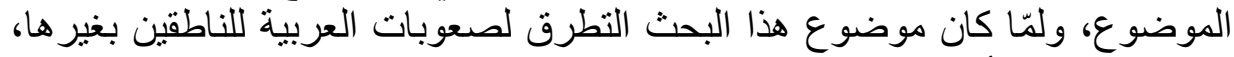

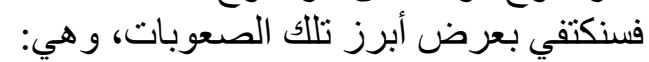

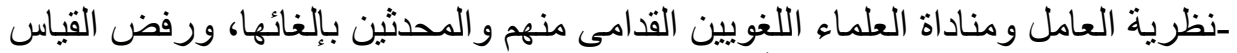

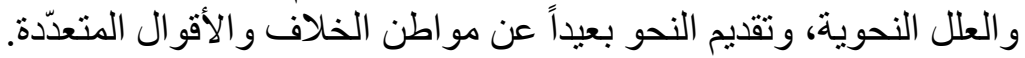

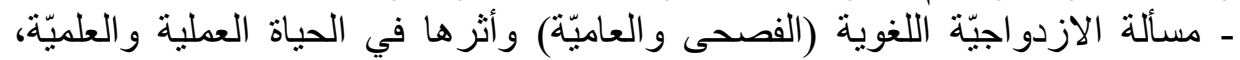

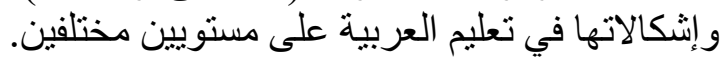
ـ مظاهر تقعيد اللغة العربية الفصحى بقو العين انين نحويّة وصرفيّة أكثر ما تهمّ المتخصصون

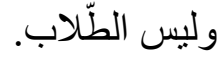

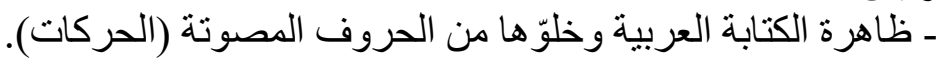

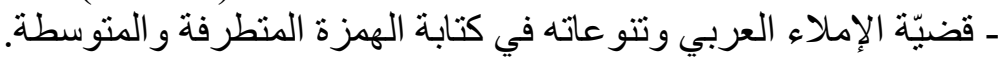

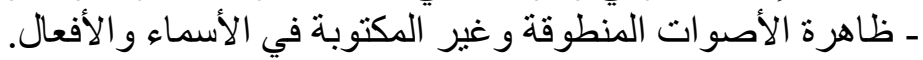
ـ ـ نظام الإعراب و أثره في البناء البناء التركيبي العربي.

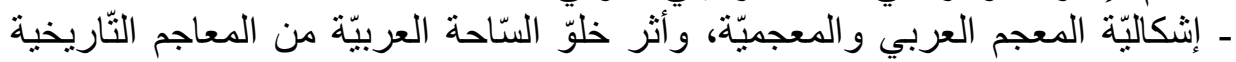
المناسبة لتعليم العربيّة.

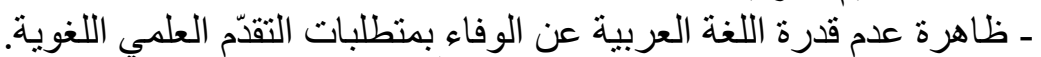

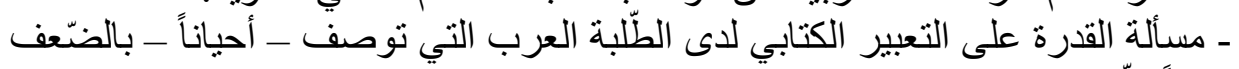

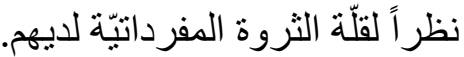
ـ الاتجاه الفلسفي و العقلي، واتباع مناهج المتكلمين و الفقهاء في در اسة النحو وتقديمه.

ـ ـ الإعداد الثقافي لمعلّم اللغة العربية للناطقين بغير ها "، د. خليل أحمد عمايرة ندوة تطوير بر امج إعداد معلمي اللغة العربية للناطقين بلغات أخرى، الخرافئ الخرطوم. 
ـ ظهور الدلالات المستحدثة لبعض المفردات العربية، غير المثبتة في المعاجم العربيّة (قضيّة المعنى و الدّلالة).



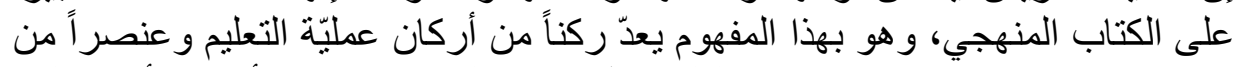





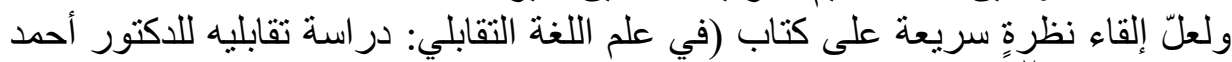

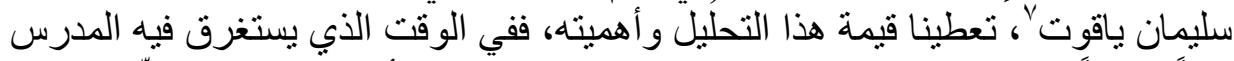

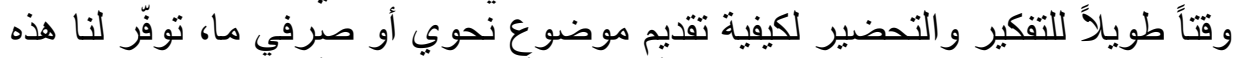

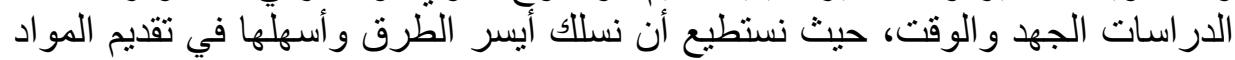

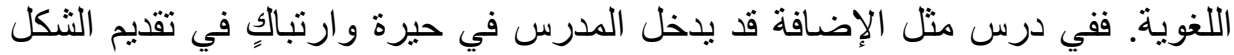

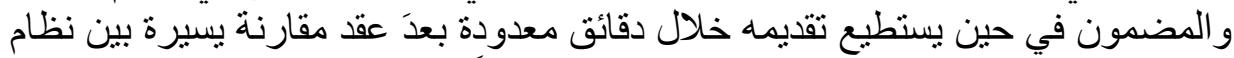

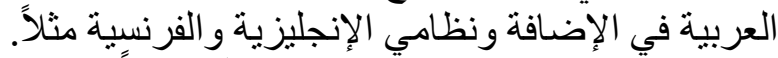

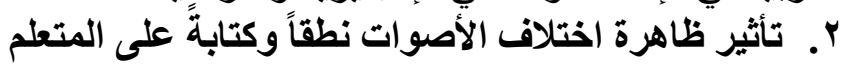

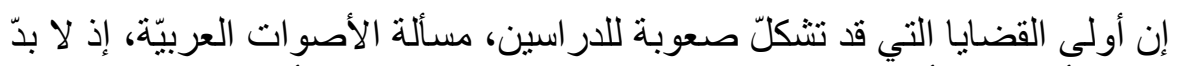

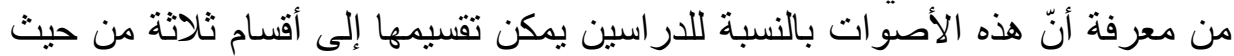

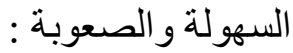

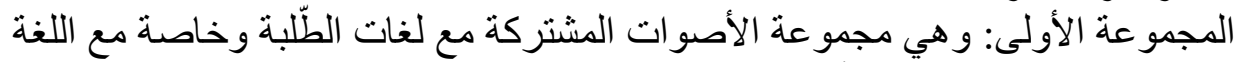



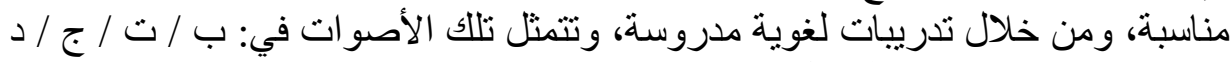

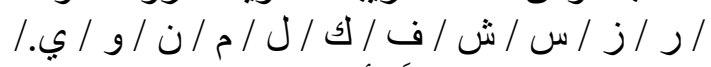

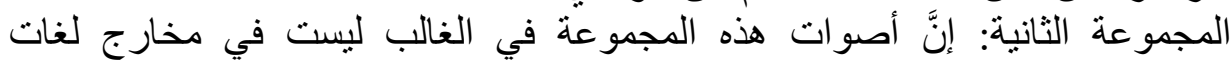

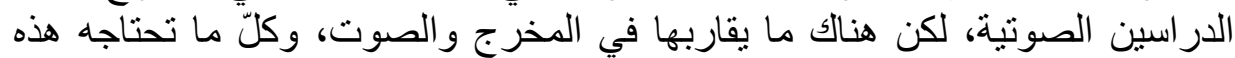

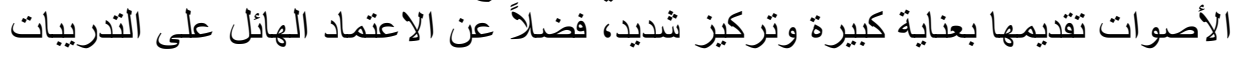

ه ـ مجد محمد باكير البرازي، مشكلات اللغة العربية المعاصرة، مكتبة الر اسلة، عمان - الأردن،

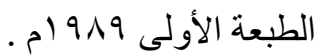

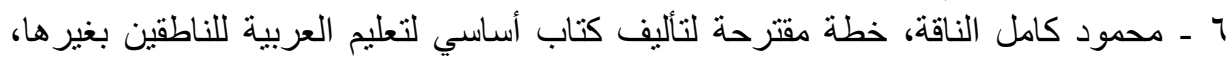

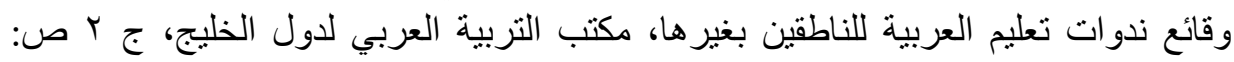
و V ـ ـ د. أحمد باقوت سليمان، في علم اللغة التقابلي: دار المعرفة الجامعية ـ الإسكندرية ـ 


\section{العربي الحضراوي}

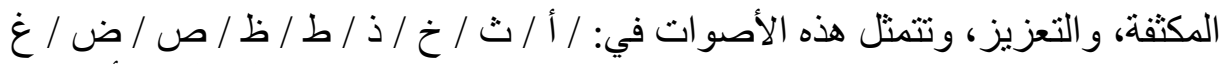

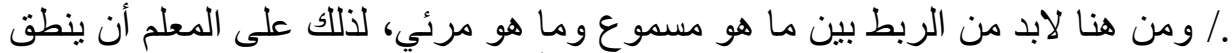

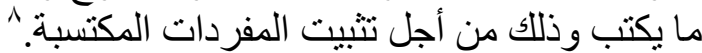

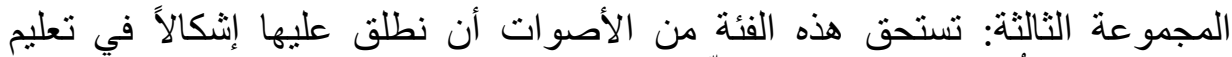

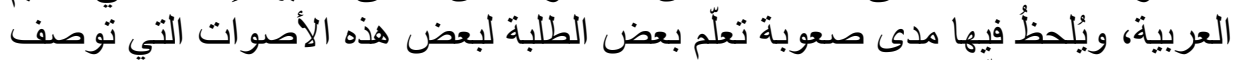

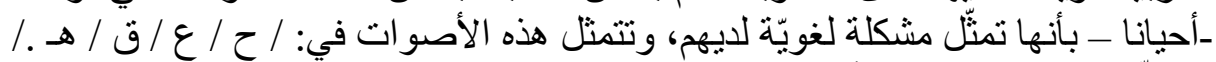

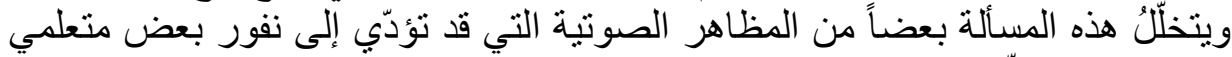

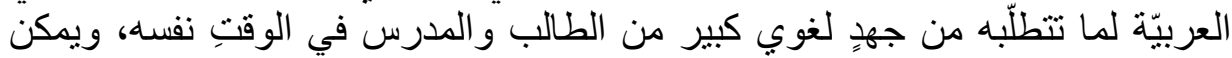

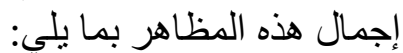

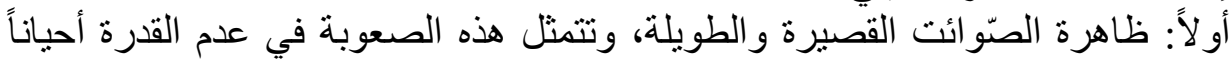

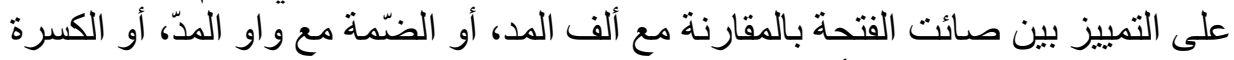

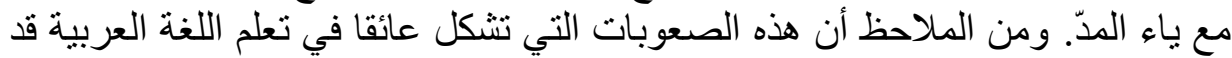

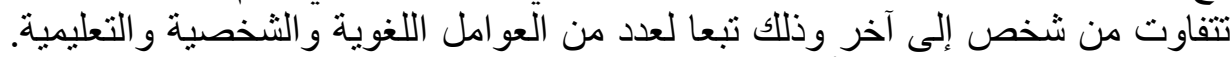

ويرى علماء اللغة التطبيقية.

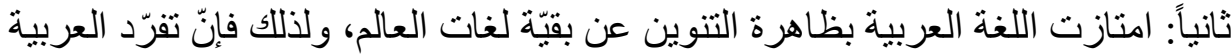




ثالثاً: ظاهرة التشابه الصوتي بينَ صوت الألف الممدودة و المقصورة، إذ إنّ صوتيهما

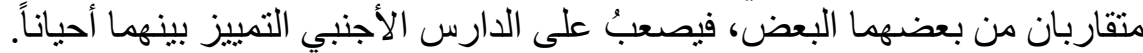

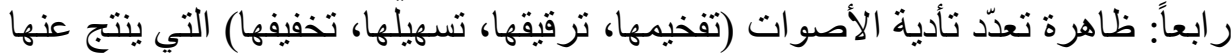

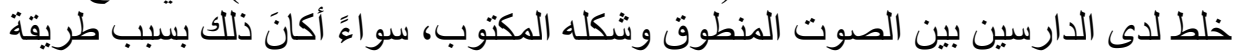

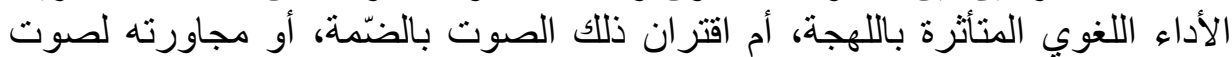

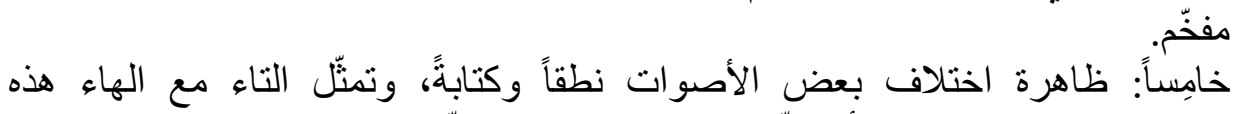



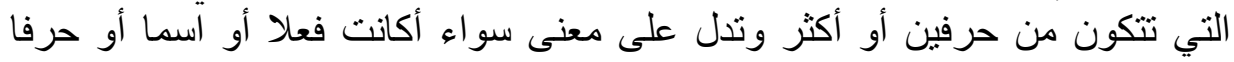

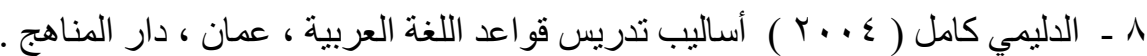

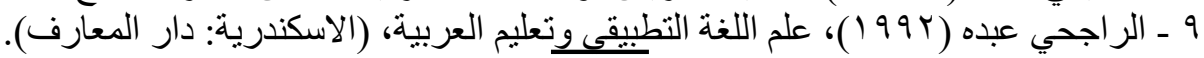


بمعنى أن يكون الطالب قادر على أن يستخدم الكلمة المناسبة في المكان المناسب مع

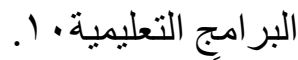

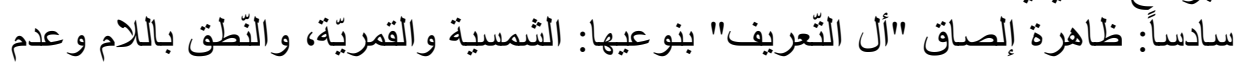

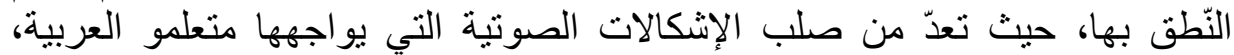

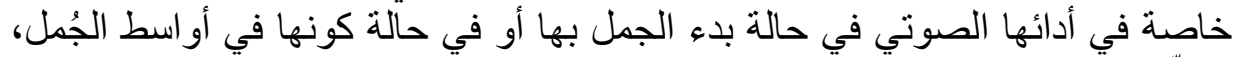

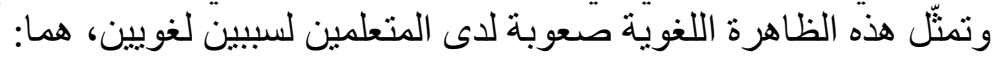
ـ اشتنر الك النوعين بالثكل الكتابي (الرسم الإملانئي).

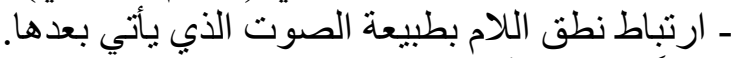

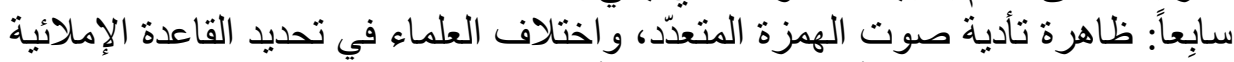

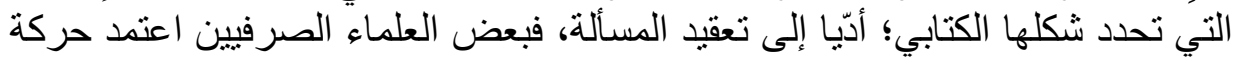

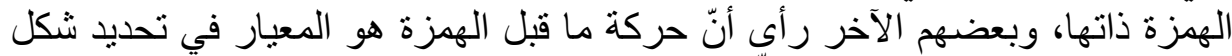

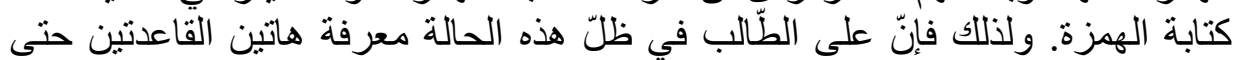

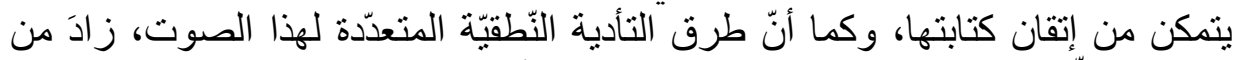

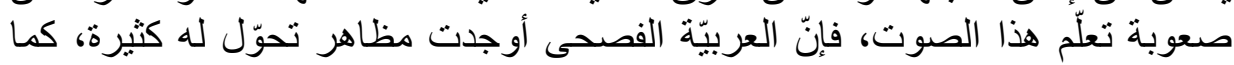
فعلت اللغة الدّارجة.

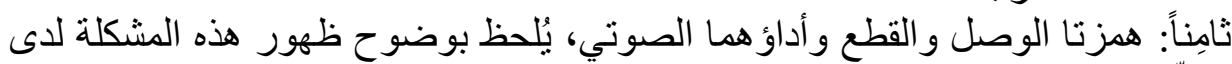

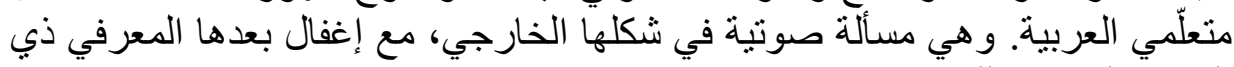
الجانب التركيبي للغة.

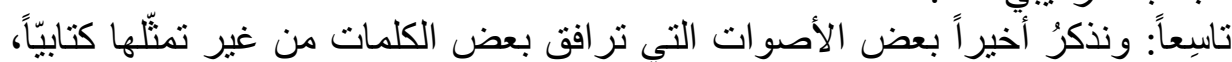



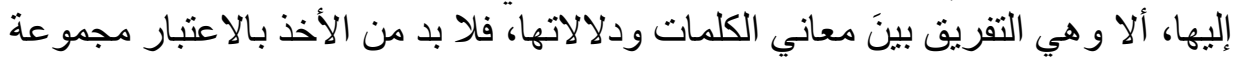

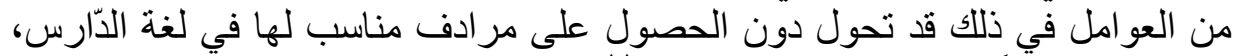

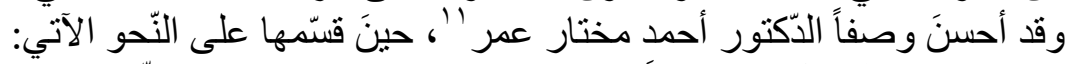

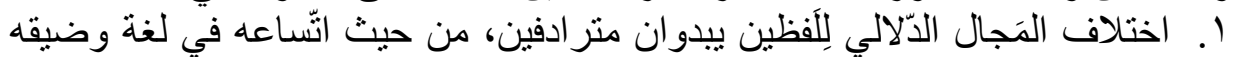

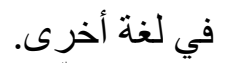

r. اختلاف التّّزيع السياقي لكلمتين تبدوان متر ادفتين في اللغة، لكنّ تطبيقاتهما في الاستعمال أو في سياقاتهما تبدو مختلفة لتبن.

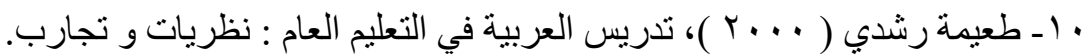

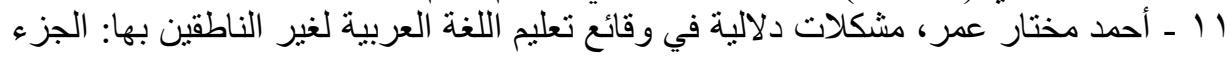

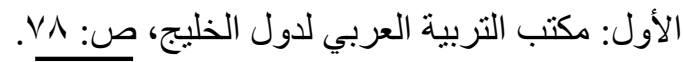




\section{العربي الحضراوي}

r. الاستخدامات المجازية للمفردات، لذلك لا تصحّ في أيّة حالٍ من الأحو ال التّرجمة

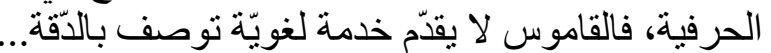



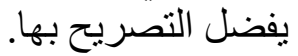

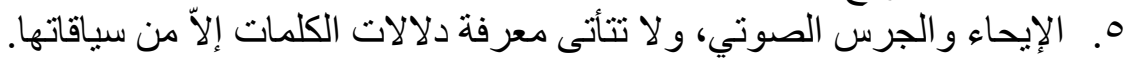

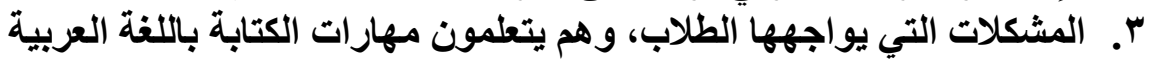

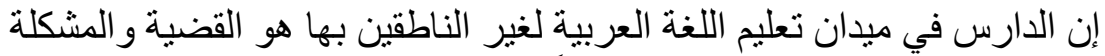

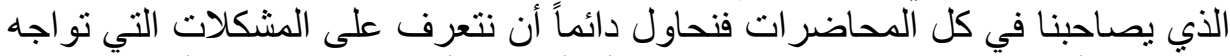

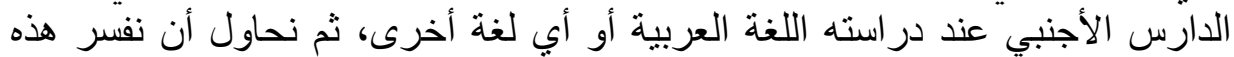
المشكلات وبعدها نضع العلاج المناسب.

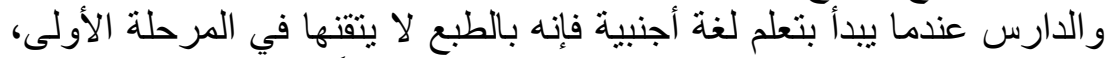

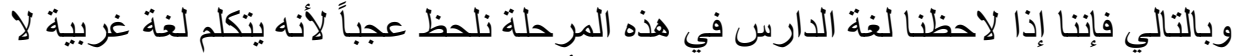

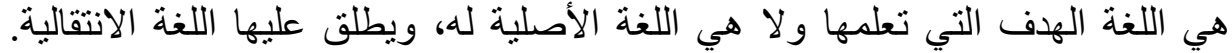

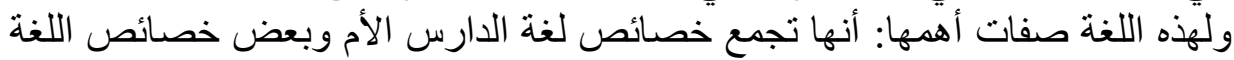

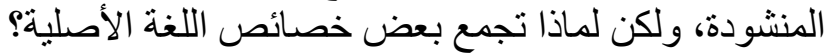

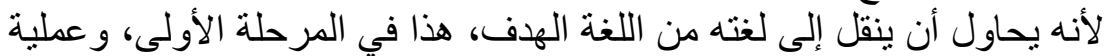

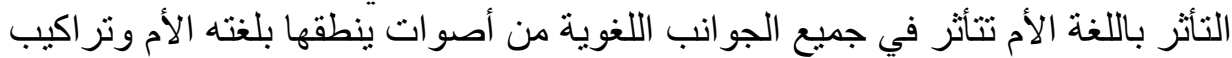

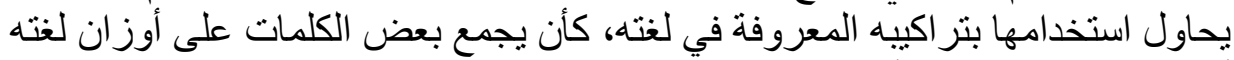
أو غير ذللك فهو يحاول أن يعمم قاعدة لتفيه النفسه.

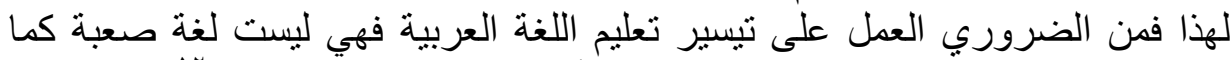

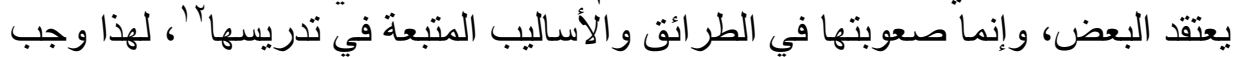

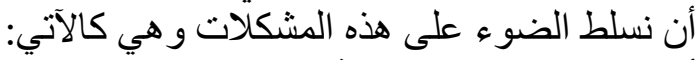
أولا: من المشكلات العامة: المباء ازدحام الفصول بالطلاب.

انتماء طلاب الفصل إلى خلفيات لغوية وثقافية متعددة.

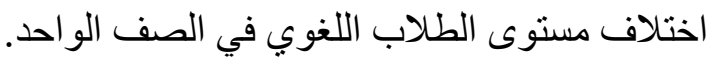
كثرة الفروق الفردية بين الطلاب. ضعف تجاوب الطلاب مع المدرس.



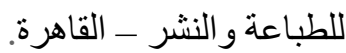




$$
\text { عدم اهتمام الطلاب بمظهر هم. }
$$

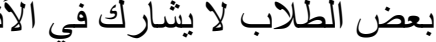

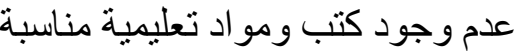

$$
\bullet
$$

ثنانيا: من المشكلات الخاصة:

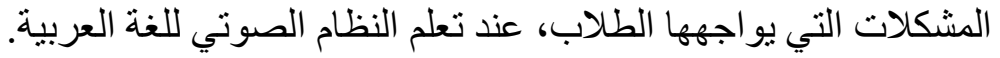

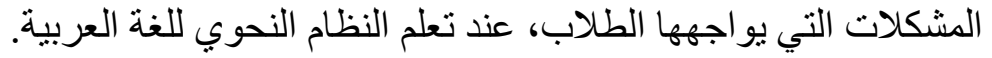

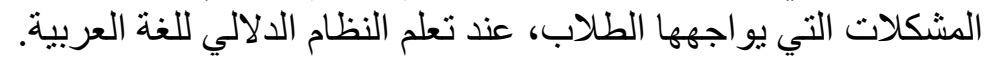

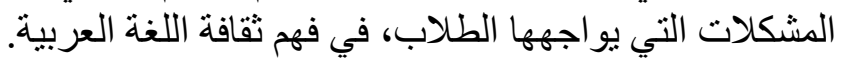

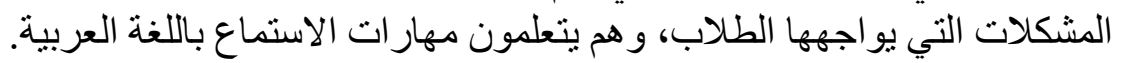

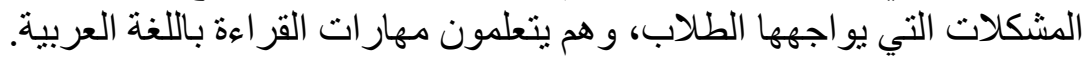

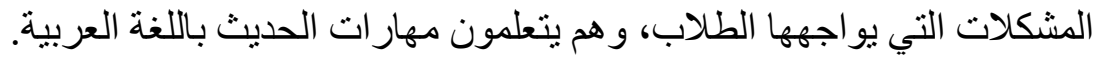

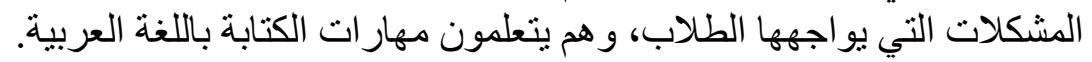

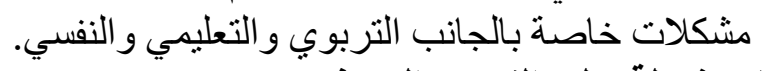

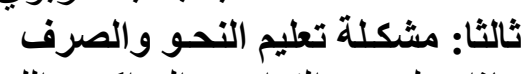

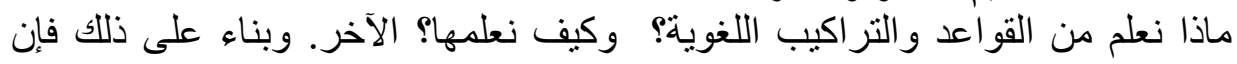

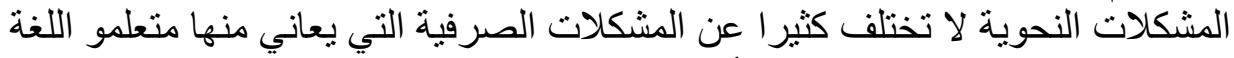



$$
\text { ولاختيار محتوي در اسي يجب أن نحدد ما يلي: }
$$

سا ـ الغالي ناصر (1991 (19)، اسس اعداد الكتب التعليمية لغير الناطقين بالعربية، (دار 


$$
\begin{aligned}
& \text { ا - - - أهداف المقرر. } \\
& \text { ب- الو الوقت المتاح لتعليم المقرر. }
\end{aligned}
$$

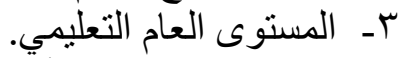

$$
\begin{aligned}
& \text { عـ - نوع المدرسة فيجب أن يكون مؤثر أ في اختيار المحتوى. } \\
& \text { رابعا: مشكلات الكتابة }
\end{aligned}
$$

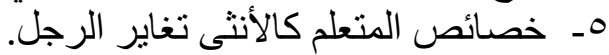

يذهب كثير من الباحثين إلى أن أول ما يواجه المتعلم للغة العربية هو تشابه

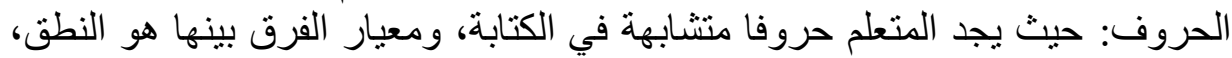

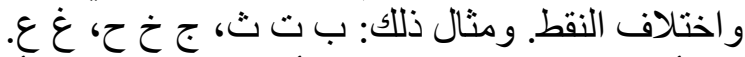

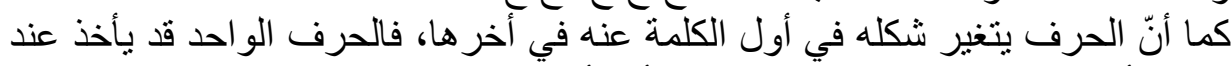

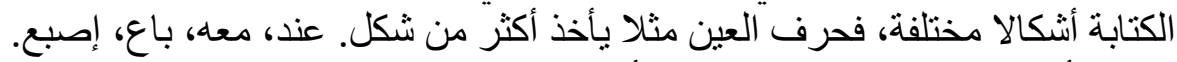

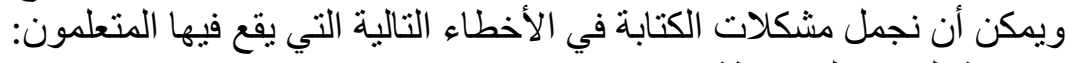

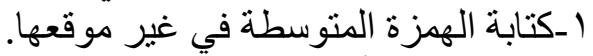
r-إبدال حرف بأخر.

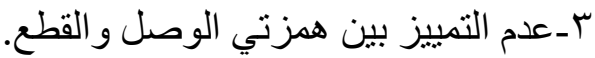
ع ـفصل ما حقه الوصل. ๑ـحذف حرف أو أكثر من الكلمة. 7-إضافة حرف أو أكثر في الكلمة.

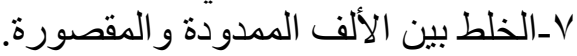

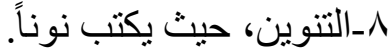
9 هـكتابة همزة المد همزة حكابة عادية. • 1 ـ ـكتابة التاء المفتوحة تاءة التاء مربوطة عادية.

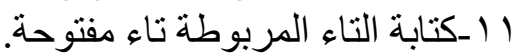

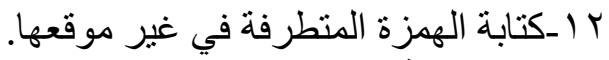
خامسا: مشكلة الدارسين: 1 - خلفية الدارسين الثقافية و العلمية. r-خلفية الدارسين الاجتماعية.

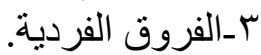
ـــخلفية الدارسين اللغوية بمعنى لغتهم الأم. هـاختلاف دو افع الدارسين و أهدافهم من تعلم العربية. 7-اختلاف جنسياتهم. 


\section{سادسا: مشكلة المعلمين:}

ا ـأن القائمين على تدريس المعين: اللغة العربية لغير الناطقين بها غالبا غير مؤهلين عملياً

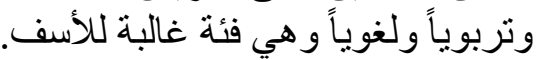

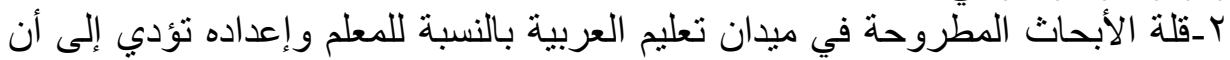





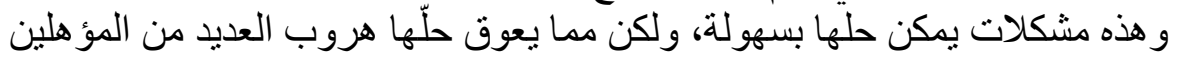

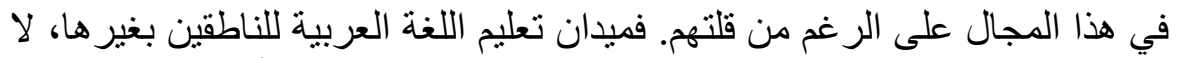

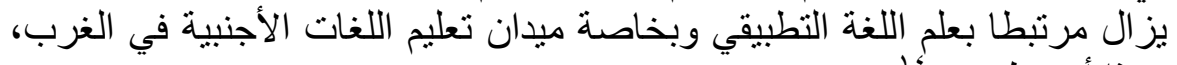

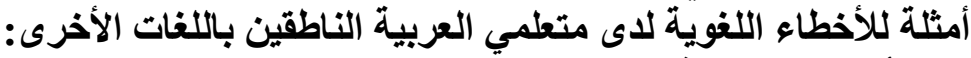

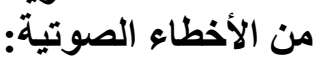

الصواب

رجنا

عمارة

حيوان

الحماية

نظر
الخطأ

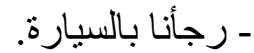
- - مذه إمارة جميلة. ـ الفيل هيو ان كبير. ـ عاثو ا تحت الهماية. ـ - نذر إلى الهاتف. ـ ـ هذا الفيل دخم. الأخطاء في التر اكيب النحوية. الثالثة ـ الساعة ثناثة.

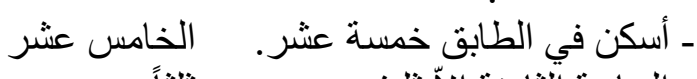

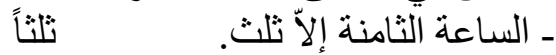
في السيارة العطلة العيارة الثهري بصديقي


- مبدأت عطلة الصيفية. - منى يبدأ الامتحان الثهير؟ من الأخطاء في المفردات:

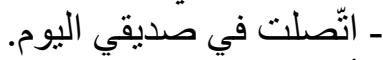
عنه

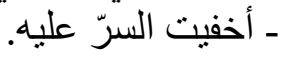

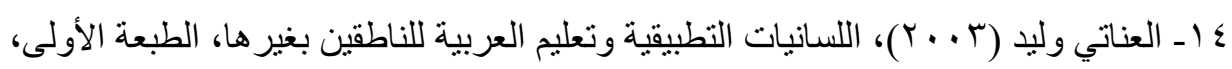

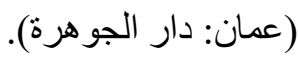




\section{العربي الحضراوي}

\begin{tabular}{|c|c|}
\hline للك & هل عندك أو لاد؟ \\
\hline لافر & ظر ملفت للنظر \\
\hline جب & \\
\hline
\end{tabular}

إن تعليم اللغة العربية لغير الناطقين بها يقوم على العلاقة بين المتعلم و المنهاج

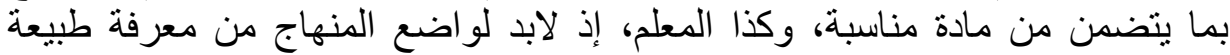

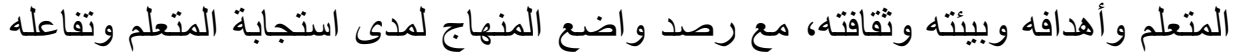

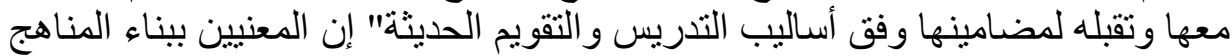

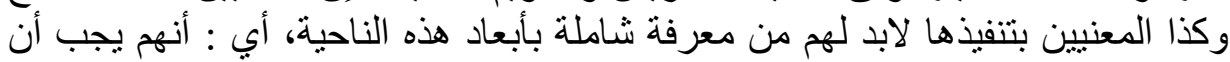

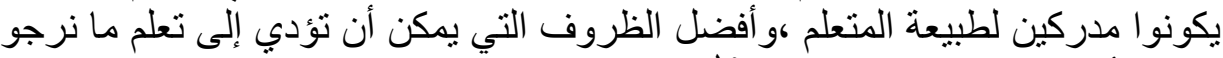

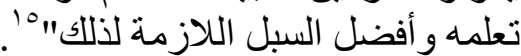

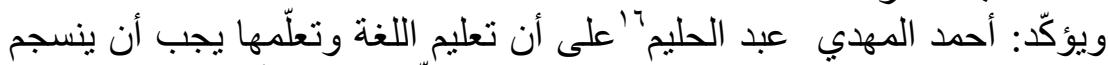

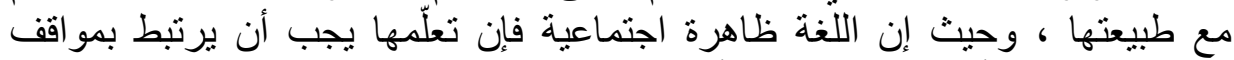

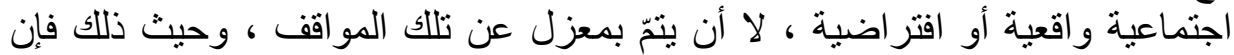

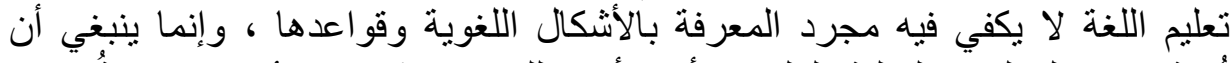

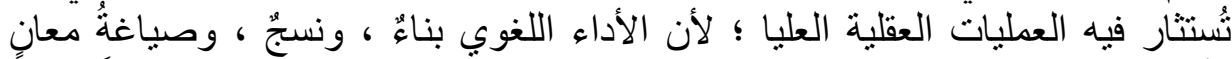

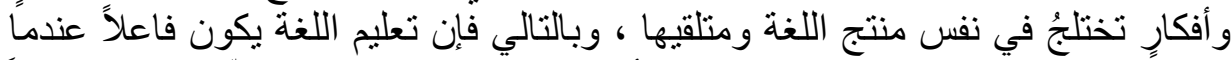

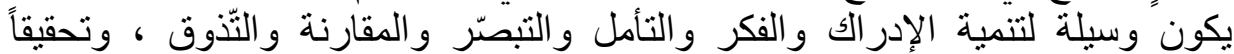


وذلك تحقيقا لمفهوم التكامل في الدرس اللغوي بمفهومه الثنامل، فمفهوم

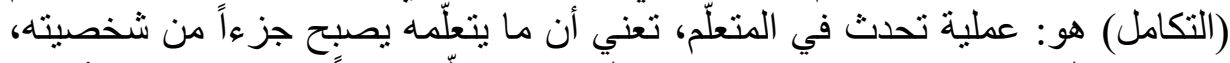

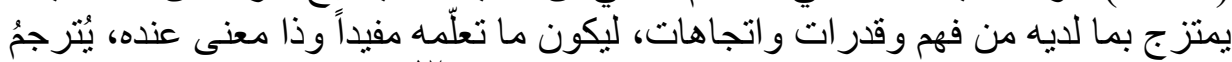

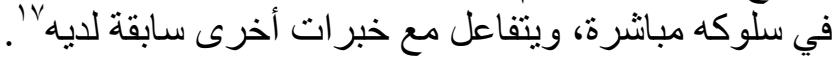

ه 1 ـ المناهج بين النظرية و التطبيق، أحمد حسين اللقاني، ص: 9 با، علم الكتب، القاهرة، ط؛، . 1990

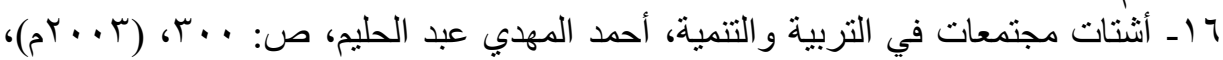
القاهرة: دار الفكر العربي.

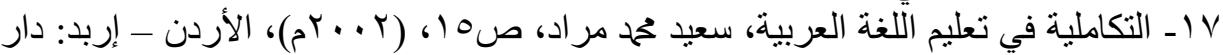


لذلك وجب الأخذ بعين الاعتبار أن تكون مادة النصوص إنسانية، وذات أثر في

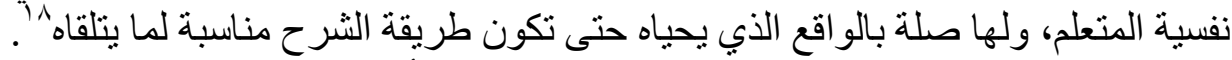

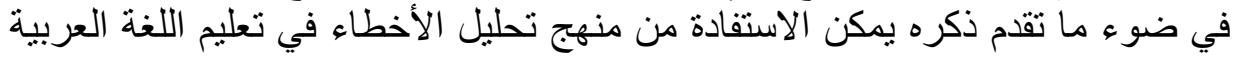

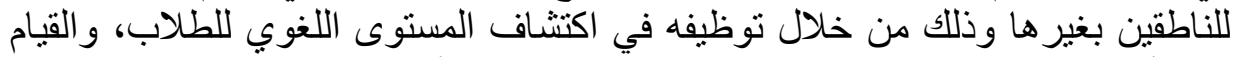

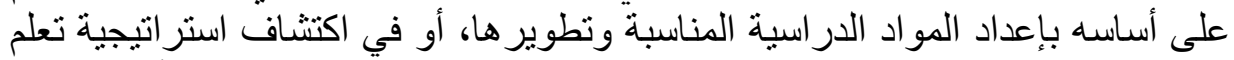

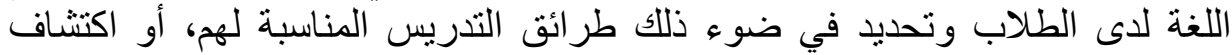

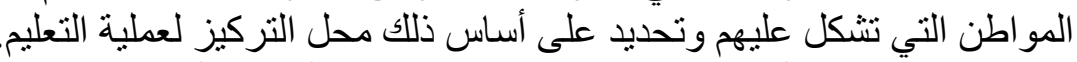

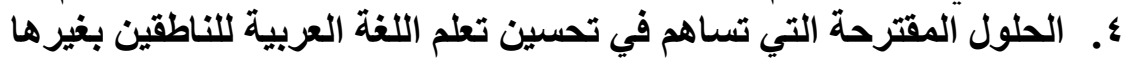

اــ أدوار المعلم في المدخل القائم على المَهمة التعليمية

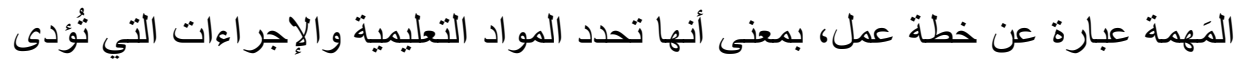
في أثناء الدرس، فإن اختلف النشاط الفعلي مع المخطط له، فقد لا ينتج عن المَهمة سلوك الته تو اصلي.

تركز المَهمة أساسا على المعنى، بمعنى أنها تسعى إلى دمج المتعلمين في استخدام اللغة إنهاء

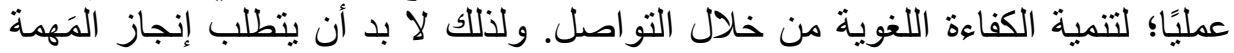

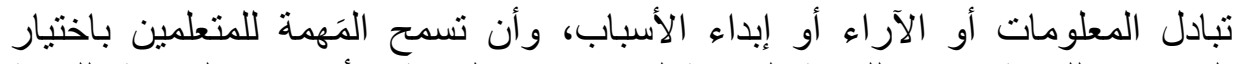

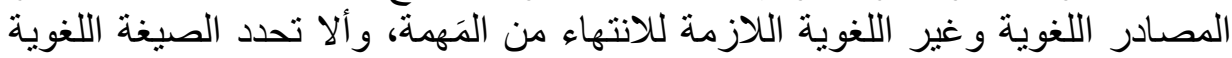

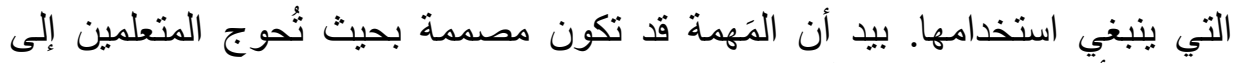
استخدام ألفاظ تتتمي إلى حقل دلالي معين واستخدام تر اكيب لغوية محددة، لكن الخيار في كل الحالات يُترك لكي للمعلم و المتعلمين.

ولهذا يقوم المعلم بأدوار متعددة في المدخل القائم على المَهمة في تعلم اللغة وتعليمها،



اختيار المهام وترتيبها.

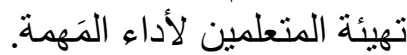
لفت انتباه المتعلمين إلى الصيغة الصغئة اللغوية المستهدفة. تدريب المتعلمين على الاستر اتيجيات اللازمة لأداء المئهة المَهمة.

11 اـ أثر التخطيط اللغوي في بناء منهاج اللغة العربية للناطقين بغير ها-زيد خليل القرابة، ص:

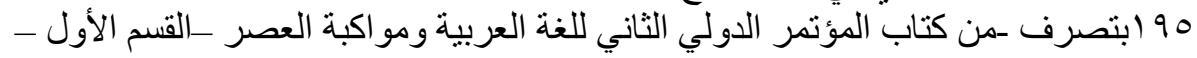
المحور الرابع.

19 Oxford, R. L. (2006). Task-Based Language Teaching and Learning: An Overview. 


\section{العربي الحضراوي}

$$
\begin{aligned}
& \text { • توجيه المتعلمين في أثناء أداء المَهمة. }
\end{aligned}
$$

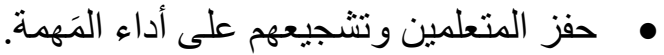

$$
\begin{aligned}
& \text { تقديم المساعدة و العون عند الحاجة. } \\
& \text { r ـ أدوار المتعلم في المدخل القائم على المَهمة }
\end{aligned}
$$

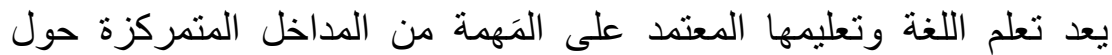

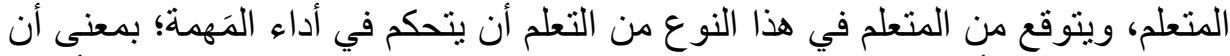

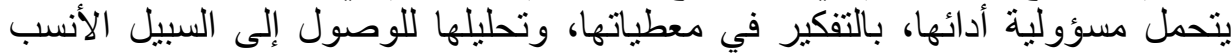

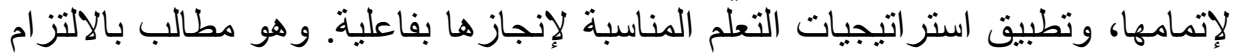

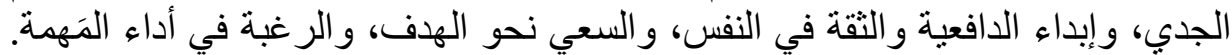

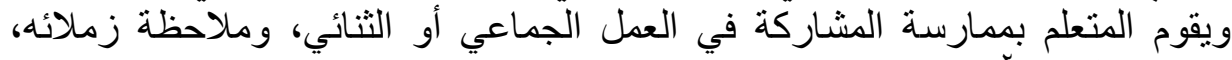
و التقويم الذاتي ‘.

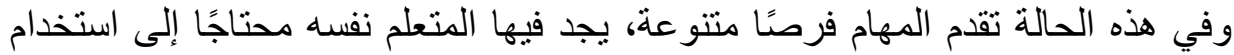

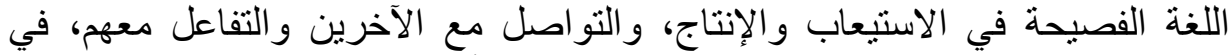

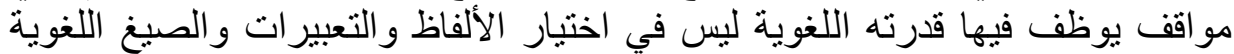

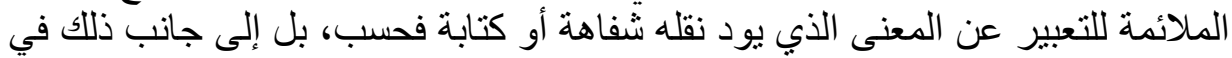

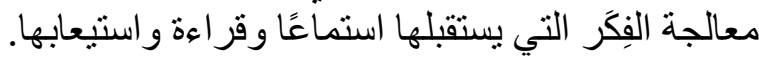

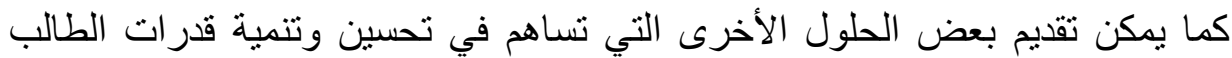
الأجنبي الر اغب في تعلم اللغنة العربية العربية ومن بينها: ا - بناء برامج قائمة على مدخل تعلم اللغة وتعليمها القائم على التواصل لتعليم اللغة العربية، واختبار فاعليتها. r- تقديم مقترحات عملية بتصميم مهام في تعليم اللغة العربية في مستويات الدارسين المختلفة.

r- تجريب استر اتيجيات و أنماط محددة في تعليم اللغة العربية وفقًا لمدخل تعلم اللغة وتعليمها القائم على التَهمة.

عـ تجريب فاعلية بعض أنواع المهام في تنمية مهار ات لغوية محددة في مستويات لغوية مختلفة.

20 Ibid. 
0ـ إعداد مدرسين متخصصين يتمتعون بمهار ات خاصة لتعليم العربية لغير الناطقين

7- إنشاء معاهد خاصة لهذه الغاية تكون مزودة بالوسائل التكنولوجية اللازمة السمعية و البصرية

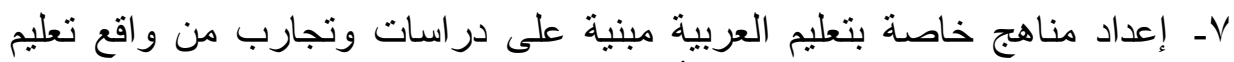

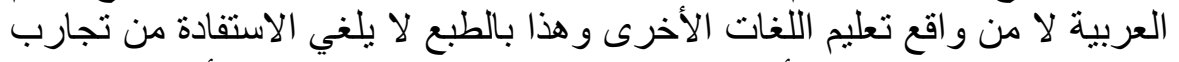

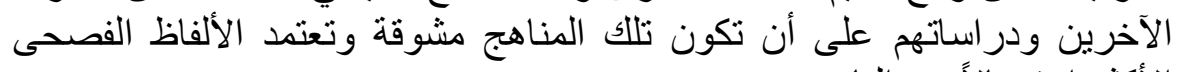
الأكثر استعمالاً بين الناس.

أكدت النتائج وجود الكثير من التحديات التي تواجه تعليم اللغة العربية للناطقين بغير ها، وكذلك وجود العديد من التحديات التي تنتعلق بإعداد معلم اللغة التهائ العربية للناطقين بغير ها وتتميته المهنية.

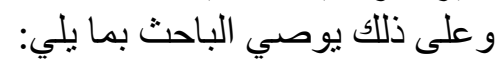

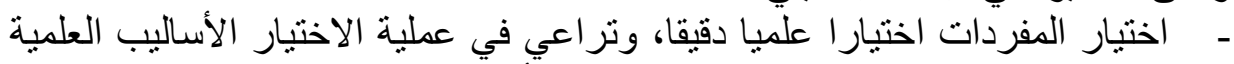

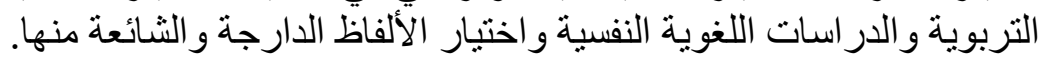

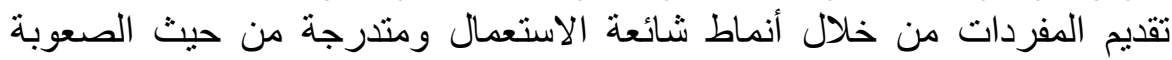

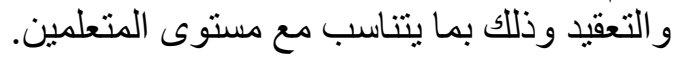
تعليم المفردات من خلال سياقات لغوية مختلفة وتقديم المفردات من خلال الصور التوضيحية. - اختيار المفردات ذات الطبيعة الحوارية و القريية من المفاهيم الحضارية و التقافية.

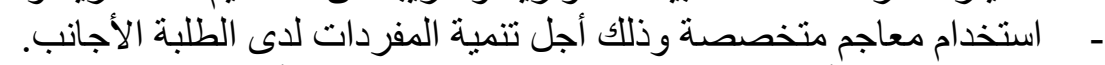

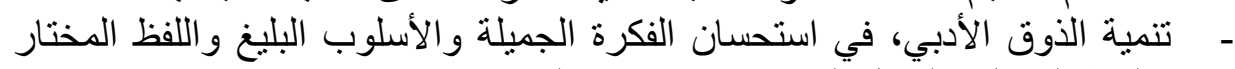

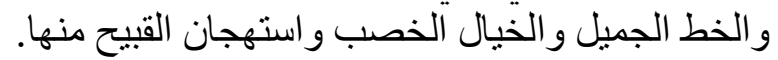

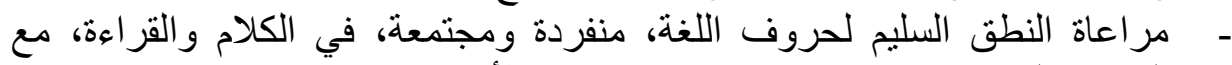

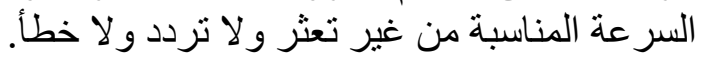
- تعويد المتعلم على الفصحى في الحديث والكتابة وتحسين اسلوب التعبير الكلامي و الكتابي. 


\section{العربي الحضراوي}

المصادر والمراجع : المدبع

العصيلي عبد العزيز بن إبراهيم: أساسيات تعليم اللغة العربية للناطقين بلغات

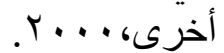

الدليمي كامل: أساليب تدريس قو اعد اللغة العربية، عمان، دار المناهج، ؟ ... الر اجحي عبده: علم اللغة التطبيقي وتعليم العربية، الاسكندرية: دار المعارف، ب99 ا. الحديدي على: مشكلة تعليم اللغة العربية لغير العرب ـ دار الكتاب العربي للطباعة

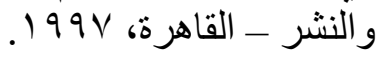

الغالي ناصر: اسس اعداد الكتب التعليمية لغير الناطقين بالعربية، (دار الاعتصام)، .1991

العناتي وليد: اللسانيات التطبيقية وتعليم العربية للناطقين بغير ها، الطبعة الأولى، عمان:

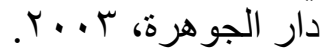

أحمد حسين اللقاني: المناهج بين النظرية والتطبيق، علم الكتب، القاهرة، طع، 990 (م. أحمد المهري عبد الحليم: أثتات مجتمعات في التربية والتتمية، القاهرة: دار الفكر

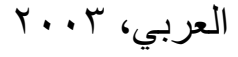

أحمد مختار عمر : مشكلات دلالية في وقائع تعليم اللغة العربية لغير الناطقين بها: الجزء الأول: مكتب التربية العربي لدول دلئل الخليج.

أحمد ياقوت سليمان: في علم اللغة التقابلي، دار المعرفة الجامعية ـ الإسكندرية ـ .1994

مجد محمد باكير البرازي: مشكلات اللغة العربية المعاصرة، مكتبة الراسلة، عمان -



محمود كامل الناقة: خطة مقترحة لتأليف كتاب أساسي لتعليم العربية للناطقين بغير ها،

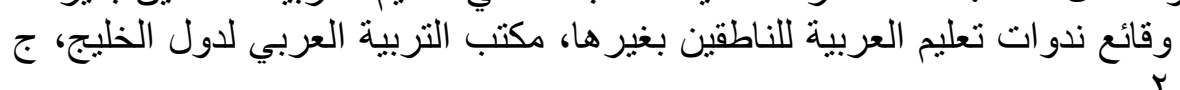

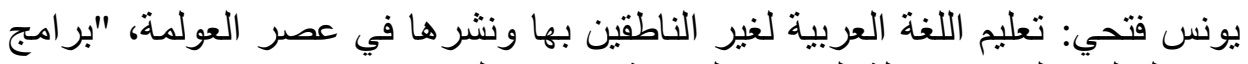

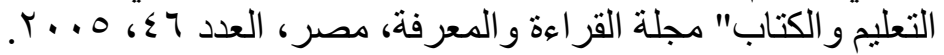


خليل أحمد عمايرة: الإعداد الثقافي لمعلّم اللغة العربية للناطقين بغيرها، ندوة تطوبر

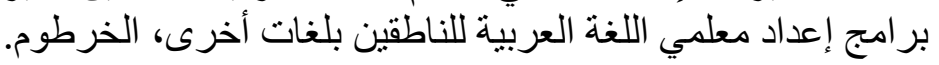



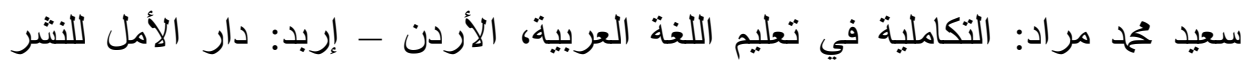

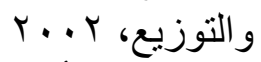

زيد خليل القرابة: أثر التخطيط اللغوي في بناء منهاج اللغة العربية للناطقين بغير ها، من

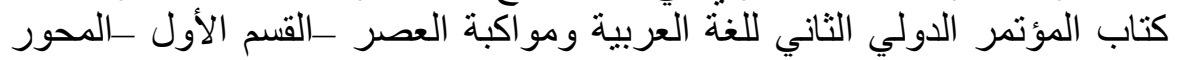
الر ابع.

Oxford, R. L. (2006). Task-Based Language Teaching and Learning : An Overview 
العربي الحضراوي

7 